\title{
Target Selection Signals for Arm Reaching in the Posterior Parietal Cortex
}

\author{
Hansjörg Scherberger and Richard A. Andersen \\ Division of Biology, California Institute of Technology, Pasadena, California 91125
}

\begin{abstract}
The selection of visual stimuli as a target for a motor action may depend on external as well as internal variables. The parietal reach region (PRR) in the posterior parietal cortex plays an important role in the transformation of visual information into reach movement plans. We asked how neurons in PRR of macaque monkeys reflect the decision process of selecting one of two visual stimuli as a target for a reach movement. Spiking activity was recorded while the animal performed a free-choice task with one target presented in the preferred direction and the other in the off direction of the cell. Stimulus-onset asynchrony (SOA) was adjusted to ensure that both targets were selected equally often and the amount of reward was fixed. Neural activity in PRR was action specific for arm reaching and reflected the timing of the SOA as well as the selection of reach targets. In individual trials, activity was strongly linked to the choice of the animal, and, for the majority of cells, target selections could be predicted from activity in the stimulation or planning period, i.e., before the movement started. Many neurons were gain modulated by the fixation position, but gain modulation did not influence the target selection process directly. Finally, it was found that target selection for saccade movements was only weakly represented in PRR. These findings suggest that PRR is involved in decision making for reach movements and that separate cortical networks exist for target selection of different types of action.
\end{abstract}

Key words: sensorimotor transformation; motor system; movement planning; decision making; monkey; parietal reach region

\section{Introduction}

The posterior parietal cortex (PPC) plays a crucial role for the planning of movements on the basis of sensory information. $\mathrm{Pa}-$ tient studies, human functional magnetic resonance imaging experiments, and electrophysiological recordings in nonhuman primates have shown that the PPC is neither purely sensory nor motor but is an area that encodes cognitive functions related to action (Balint, 1909; Mountcastle et al., 1975; Geshwind and Damasio, 1985; Andersen, 1987; Goodale and Milner, 1992; Connolly et al., 2000; Rushworth et al., 2001; Musallam et al., 2004). Several distinguishable subregions have been identified in the PPC that are specialized for the planning of eye, arm, and hand movements (Mountcastle et al., 1975; Gnadt and Andersen, 1988; Sakata et al., 1995; Snyder et al., 1997). One of them, the parietal reach region (PRR) encodes cognitive signals related to arm reaching, such as the direction of intended arm movements and the expected value associated with the execution of such actions (Snyder et al., 1997; Batista et al., 1999; Buneo et al., 2002; Musallam et al., 2004).

The presence of sensory- and movement-specific representa-

Received Jan. 3, 2006; revised Jan. 10, 2007; accepted Jan. 10, 2007

This work was supported by the Christopher Reeve Paralysis Foundation, the James G. Boswell Foundation, Defense Advanced Research Projects Agency, Office of Naval Research, Sloan-Swartz Center for Theoretical Neurobiology at the California Institute of Technology, and the National Eye Institute. We thank B. G. Grieve, K. Pejsa, and L. Martel for animal care, T. Yao and C. Marks for administrative assistance, and V. Shcherbatyuk for technica support.

Correspondence should be addressed to Hansjörg Scherberger at his present address: Institute of Neuroinformatics, University and Federal Institute of Technology of Zürich, CH-8057 Zürich, Switzerland. E-mail: hjs@ini.phys.ethz.ch.

DOI:10.1523/JNEUROSCI.4274-06.2007

Copyright $\odot 2007$ Society for Neuroscience $\quad 0270-6474 / 07 / 272001-12 \$ 15.00 / 0$ tions together with high-level cognitive signals suggests that the PPC plays an important role for decision making related to action. Using behavioral paradigms that probe target detection, expected utility, matching behavior, and internal choices, this role has been demonstrated in the lateral intraparietal area (LIP), a subregion of PPC involved in the planning of eye movements (Shadlen and Newsome, 1996; Platt and Glimcher, 1999; Coe et al., 2002; Sugrue et al., 2004). Additionally, experiments in PRR showed activity related to expected value (Musallam et al., 2004). It is also clear that decision making for action is a distributed process that involves many brain areas, including frontal and subcortical regions (Shadlen and Newsome, 1996; Horwitz and Newsome, 1999; Kim and Shadlen, 1999; Schultz and Dickinson, 2000; Schall, 2001; Coe et al., 2002; Cisek and Kalaska, 2005). The terms "target selection," "decision," and "choice" shall all mean the selection of a motor plan from several possible options throughout this paper.

We asked whether target selection for reach movements is reflected in the spiking activity of PRR and to what extent such a representation is specific for arm reaching as opposed to saccade movements. Using a choice task in which two visual stimuli were presented equidistantly on opposite sides of a fixation position, animals had to select one of them as a reach target (Scherberger et al., 2003a). It was found that spiking activity in PRR represented the choice of the selected target in addition to a smaller visual response, thus confirming the involvement of PRR in target selection. Spiking activity in PRR was specific for the selection of reach targets and was substantially diminished when saccade targets were selected. Variation of eye position in space introduced a gain modulation of the neuronal activity that was identical in the 
single-target and the choice task, consistent with a role of gain fields for coordinate transformation.

Parts of this work have been published previously in abstract form (Scherberger and Andersen, 2001).

\section{Materials and Methods}

Subjects. Two male rhesus monkeys (Macaca mulatta) participated in this study (animals C and D). To prepare for the recording experiments, three surgical procedures were performed under sterile conditions and general anesthesia (induction with $10 \mathrm{mg} / \mathrm{kg}$ ketamine, i.m., followed by intubation, isofluorane $1-2 \%$, and analgesia with $0.01 \mathrm{mg} / \mathrm{kg}$ buprenorphene, s.c.). Heart and respiration rate, electrocardiogram, $\mathrm{O}_{2}$ saturation, and body temperature were monitored continuously. In a first procedure, a custom-made stainless steel or titanium head post and a dental acrylic head cap (Coralite Duz-All; Bosworth, Skokie, IL) were implanted onto the skull of each animal. Next, a scleral search coil was implanted in one eye to monitor the animal's eye position (Judge et al., 1980). Finally, a left or right recording chamber was implanted onto the skull (right hemisphere of animal C and both hemispheres of animal D) and fixed to the dental acrylic head cap (approximate stereotaxic location, $12 \mathrm{~mm}$ lateral from midline and $6 \mathrm{~mm}$ posterior to the interaural line). Systemic antibiotics and analgesics were administered for several days after each surgery, and the animals were allowed to recover for at least 1 week before behavioral training or recording experiments began. All procedures were in accordance with the $\mathrm{Na}$ tional Institutes of Health guidelines and were approved by the California Institute of Technology Institutional Animal Care and Use Committee.

Setup. Monkeys were seated upright in individually adjustable primate chairs, and the head was fixed with a head-holder apparatus that rigidly connected the animal's head post with the chair. One arm was partially immobilized at the elbow with a restraining band to ensure the monkeys reached only with the limb contralateral to the recording site in PRR.

Animals were trained to touch buttons $(3.7 \mathrm{~cm}$ diameter) that were placed on a board in front of the animal at a distance of $26 \mathrm{~cm}$ (three horizontal rows of five buttons; spacing of $16^{\circ}$ visual angle) (Fig. 1C). Each button contained a red and a green light-emitting diode (LED). The red LED instructed the animals where to look or maintain fixation, and the green LED instructed the animals where to place their hand. All reach movements were made with the arm contralateral to the recording site, while eye position was monitored using the scleral search coil technique (500 Hz sampling rate).

Experimental protocol. For a previous study, animals had been trained to perform a delayed reach and delayed saccade paradigm from a central fixation position (FP) to one of eight peripheral targets (Scherberger et al., 2005). This task was used as a search stimulus. In addition, animals were trained in the following single-target and choice task for reach and saccade movements (Fig. $1 \mathrm{~A}$ ). All trials began by fixating (within a window of $\pm 2.7^{\circ}$ ) and touching a red and green illuminated button, which we refer to as the FP. After a variable delay of 500-1000 ms, either one or two target buttons were illuminated on opposite sides of the FP while the illumination of the FP was extinguished. Target buttons were selected from the eight nearest neighbors around the FP, but each cell was tested
Reach / saccade paradigm
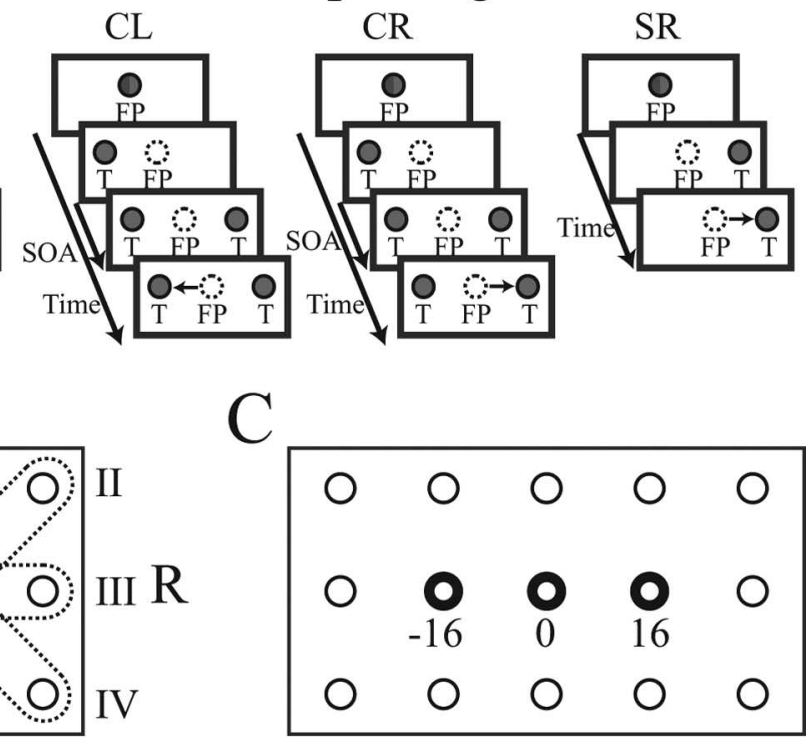

$\mathrm{E}$

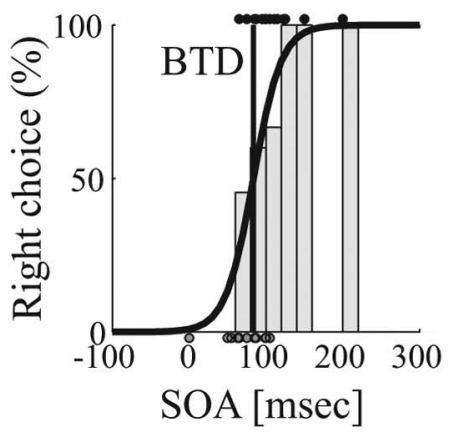

Right choice

Trials

Left choice in (circles) including three FPs (bold circles). D, SOA adaptation (PEST) during a block of 40 choice . Past leftward and rightward selections determine the future SOA. Horizontal line, BTD as determined in E. E, Psychometric unction (black curve), fitting choice probability against SOA. Histogram, Distribution of rightward selections. Dots, SOA of individual leftward (at bottom) and rightward selections (at top). Dark vertical line, BTD. (PD) of the cell, leading to four possible target pair orientations (I-IV) (Fig. $1 B$ ).

In single reach trials, the target button was illuminated in green while the FP LEDs were turned off. In response, the monkey was required to release the FP button and reach to the target button while maintaining eye fixation at the FP. In single saccade trials, the target was illuminated in red and the animal was required to fixate the target LED while continuing to press the FP button.

In choice trials, a second target of the same color was presented on the opposite side of the FP (Fig. 1A). Although the animal was always free to choose either one of the two stimuli as the movement target to receive a fixed amount of reward, we introduced a variable time delay between the presentation of the first and second target to systematically influence the animal's preference of the two targets. We refer to the time delay between the onset of the first and the second target as the stimulus onset asynchrony (SOA), which was varied from trial to trial using an adaptive staircase procedure [parameter estimation using sequential testing (PEST)] (Taylor and Creelman, 1967) (for review, see Macmillan and Creelman, 1991; Gescheider, 1997). In this adaptive procedure, the "behaviorally less preferred" target was presented earlier than the behaviorally preferred one, which increased its frequency of selection. The time of 
asynchrony was continuously adjusted between trials such that both targets were selected equally often (Fig. 1D). This time we call the balanced time delay (BTD). When both targets were presented simultaneously, the animal often had a strong bias toward one of the targets and then selected always the same target. Therefore, the use of SOA was necessary to counterbalance this bias and to receive a sufficient number of selections of either target.

Single and choice trials were considered successful if the animal acquired exactly one target by performing the required action (reaches in reach trials and saccades in saccade trials), after which a fixed amount of juice was given as a reward. Importantly, the amount of reward was held constant during each block of trials and, in particular, was independent of the animal's choice (Platt and Glimcher, 1999; Musallam et al., 2004).

To investigate the specificity of neural activity for reaches and saccades as well as the influence of the eye position, we tested each cell in four conditions of the single-target and the choice task: (1) saccade movements with the FP at straight ahead, (2) reach movements with the FP straight ahead, and reach movements with the FP shifted from straight ahead by $16^{\circ}$ to the (3) left and (4) right. Within each condition, single trials to the left (SL) and right target (SR) were interleaved with choice trials to the same targets (ratio of 1:1:2) for a total of 80-100 trials per condition (Fig. 1A), and all trials of conditions 1-4 were presented randomly interleaved. Selections in the choice task were either to the left (CL) or the right target (CR). In the up-down target orientation, we denoted the downward target as "left" and the upward target as "right" by convention. SOA adaptation was handled separately in each of the four task conditions, that is, an independent staircase procedure was processed for the choice task of each condition.

Recording. Single-unit (spiking) activity was recorded from a single varnished tungsten electrode (impedance of $1-2 \mathrm{M} \Omega$ at $1 \mathrm{kHz}$; Frederick Haer Company, Bowdoinham, ME), which was amplified, filtered (0.6$6.0 \mathrm{kHz}$ ), isolated with a time-amplitude window discriminator (BAK Electronics, Germantown, MD), and stored to disk (2.5 kHz sampling rate).

A total of 71 neurons were recorded in PRR in three hemispheres of two monkeys (animal C, right hemisphere, 24 cells; animal D, left hemisphere, 23 cells and right hemisphere, 24 cells). The approximate center of the PRR recording site was $8 \mathrm{~mm}$ posterior and $5 \mathrm{~mm}$ lateral of stereotaxic 0 (Horsley-Clarke coordinates) at depths below the superficial cortex (Buneo et al., 2002; Scherberger et al., 2003b, 2005). The correct position of the recording chamber on top of PRR was confirmed with magnetic resonance images in one animal (D).

Neurons were first examined with a delayed reach and saccade paradigm to determine their directional tuning properties (Scherberger et al., 2005). For this, animals fixated and touched the central FP before a visual cue (green for reaches, red for saccades) was presented for $300 \mathrm{~ms}$ at one of eight target positions around the FP. In the following planning period of $900 \mathrm{~ms}$ duration, the animal could plan the appropriate reach or saccade movement depending on the cue location and color but had to withhold the movement execution until the LEDs at the FP were extinguished. Correct trials were rewarded with a drop of juice.

Only neurons that showed directional tuning [based on peristimulus time histograms (PSTHs) of the eight directions] in the delayed reach or saccade task during the cue, planning, or movement period were further considered ( $87 \%$ showed tuning for reaches, $70 \%$ for saccades). The PD of the cell was determined during the experimental session ( $a d h o c$ ) as the location with the largest activity across the eight target directions. This criterion deviated by no more than one target $\left(45^{\circ}\right)$ from a later post hoc analysis that estimated the preferred direction by fitting a tuning curve [von Mises distribution (Fischer, 1993; Zar, 1999; Scherberger et al., 2005)]. The nonpreferred direction (ND) of the cell was defined as the target location opposite to the PD with respect to the FP.

After the PD was determined, neurons were tested in the decision paradigm for the target pair orientation PD-ND. Single-target and choice trials in each condition (Fig. $1 \mathrm{~A}$ ) were run randomly interleaved in the saccade and the three reach conditions (FP at $-16,0$, and $16^{\circ}$ ) (Fig. 1C).

Data analysis. The BTD for each movement type and FP was determined off-line by modeling the relationship between the target selection preference and the SOA in a psychometric function fit using the logistic distribution

$$
P(\mathrm{SOA}, \alpha, \beta)=1 /\left(1+\exp \left(\frac{\alpha-\mathrm{SOA}}{\beta}\right)\right)
$$

with $P$ denoting the probability for a rightward (or by convention upward) choice at a given SOA. Because choices are Bernoulli distributed, leftward choices have the probability $1-P$. The free parameters $\alpha$ and $\beta$ were fitted by determining the maximum likelihood of the joint distribution of all choice trials of the given condition (Treutwein, 1995). The parameter $\alpha$ then describes the SOA for which the probabilities of leftward and rightward choices were both 0.5 . This was a robust estimate for the BTD, because it was derived with equal weight on all choice trials of the given condition. Figure $1 E$ shows an example of a logistic regression, in which dots on the top and bottom depict the SOA of individual leftward and rightward responses, the histogram gives the percentages of rightward selections, and the curve displays the fitted logistic regression function.

For the analysis of neural activity, single or choice trials were aligned to the presentation of the first (T1) or second target (T2) or the start of the movement (M). PSTHs were generated using a Gaussian kernel (20 ms SD). Population plots were obtained by averaging the PSTH of individual neurons. Confidence limits of $95 \%$ were approximated from the SEM as mean $\pm 2 \times$ SEM.

The amount of prediction that can be retrieved from the spiking activity of a single neuron was estimated using a receiver operator characteristic (ROC) analysis (Green and Swets, 1966; Britten et al., 1992). The ROC analysis compared the neural activity for movements to the preferred and nonpreferred targets in a sliding window of $200 \mathrm{~ms}$ width and in time steps of $20 \mathrm{~ms}$. At each time step, the distribution of the linearly weighed firing rate in the $200 \mathrm{~ms}$ window preceding each data point was calculated for trials to the PD and to the ND (using a filter kernel that increased linearly from 0 to 5 within the window). From these two distributions, the area under the ROC curve was computed. This method is causal in the sense that the ROC value at each time point is calculated without taking future neural activity into account.

The area under the ROC curve denotes the probability $P_{\text {ROC }}$ with which an ideal observer could predict the animal's choice from the observation window. We refer to $P_{\mathrm{ROC}}$ (as a function of time) as the ROC predictability curve. Error bars for the null hypothesis of $P_{\mathrm{ROC}}=0.5$ (chance level) were obtained by a Monte Carlo method that randomly assigned trials to the PD and ND class before $P_{\mathrm{ROC}}$ was calculated. By repeating this procedure 10,000 times, the empirical distribution and $95 \%$ confidence interval for the null hypothesis of $P_{\mathrm{ROC}}=0.5$ were estimated.

To determine whether and when the neural activity for selections of the PD and ND became different during the task, we defined the separation time (ts) as the beginning of the earliest time interval for which the ROC predictability curve $P_{\text {ROC }}$ significantly exceeded chance for at least $100 \mathrm{~ms}\left(P_{\mathrm{ROC}}>0.5 ; \alpha=0.05\right)$. If this did not occur, we set ts $=\infty$.

ROC predictability curves for the population were obtained by averaging $P_{\mathrm{ROC}}$ of individual neurons. Corresponding $95 \%$ confidence intervals were estimated from the SEM as mean $\pm 2 \times$ SEM.

Finally, in the gain field analysis, we defined a gain coefficient (gc) as $\left(f_{P}-f_{N}\right) /\left(f_{P}+f_{N}\right)$ to quantify the modulation of neural activity across different FPs. There, $f_{P}$ and $f_{N}$ denoted the mean firing rate in the time interval $\mathrm{T} 1-\mathrm{H}$ (in which $\mathrm{H}$ is the end of the reach movement) when the FP was shifted along the horizontal axis by $16^{\circ}$ from straight ahead toward $\left(f_{P}\right)$ or away from the preferred target $\left(f_{N}\right)$. By this definition, gc ranged between -1 and 1 , and positive (or negative) values denoted an increase (or decrease) in firing rate as the FP was shifted along the horizontal axis toward the preferred target of the cell. In contrast, gc $=0$ indicated no modulation of activity when varying the FP.

\section{Results}

Target selection behavior

Animals performed the decision paradigm with the left arm (LA) or right arm (RA) while neural activity was recorded in PRR on 
the contralateral hemisphere (animal D, LA and RA; animal C, only LA). By changing the SOA of the two targets with an adaptive staircase procedure (PEST) (see Materials and Methods), any preference of the animal for one particular target was counterbalanced, such that leftward and rightward choices in each task condition were approximately equally frequent (Fig. $1 D$ ). This optimal SOA, which we call the balanced time delay (Fig. $1 E$ ), was also a measure of the animal's preference. A positive BTD indicated a preference to select the left target, because the right target had to be presented "BTD milliseconds" before the left one to get an equal number of leftward and rightward selections. Similarly, a BTD of 0 indicated no preference and a negative BTD a preference for the right target.

Figure 2 shows the selection preference of all tested conditions. For reach movements (top row), target selection depended on the FP, target orientation, and the arm that was used. For nonvertical target pairs (orientations II-IV), the left FP was generally associated with a rightward shift in the selection preference (decrease of BTD), whereas the preferences for the right FP were shifted to the left (increase of BTD). This dependence of selection preference from the FP was stronger in animal $D$ than animal C. For the up-down target pair (orientation I), animal D preferred the downward target (positive BTD), whereas animal $\mathrm{C}$ had no strong preference for either target (BTD close to 0). When comparing left and right arm actions (animal D), selection preference in target orientations II-IV was shifted to the left (larger BTD) for LA movements and to the right for RA movements. Selection preferences for saccade targets (bottom row) varied for different target orientations and between animals but were primarily independent of the arm type (animal D, LA and RA).

Movement times (time from FP release to target acquisition) were essentially the same in the single-target task (mean $\pm \mathrm{SD}$, $243 \pm 68 \mathrm{~ms}$ ) and the choice task (mean \pm SD, $244 \pm 75 \mathrm{~ms}$ ) and followed a unimodal distribution (Fig. 2C). Moreover, it was observed only very rarely that animals reversed the movement trajectory during execution. This suggests that the reach movement executions in the single task and the choice task are comparable. Similar findings have been reported previously for horizontal target orientations (orientation III) (Scherberger et al., 2003a).

\section{Neural activity during choice}

To illustrate neural activity during target selection, we first show an example neuron in the reach selection task (Fig. 3). Each panel shows individual spike rasters above the corresponding PSTH. Time markers below the PSTH indicate the mean appearance (across trials) of $\mathrm{T} 1, \mathrm{~T} 2, \mathrm{M}$, and $\mathrm{H}$. All trials are aligned to the appearance of the T1. The top row shows the activity in response

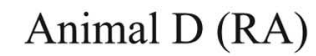

Animal C (LA)
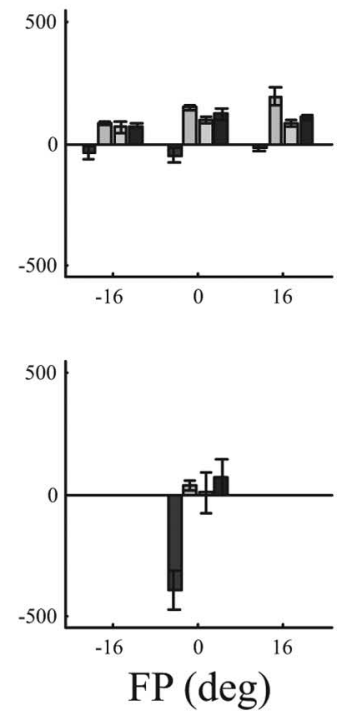

Choice
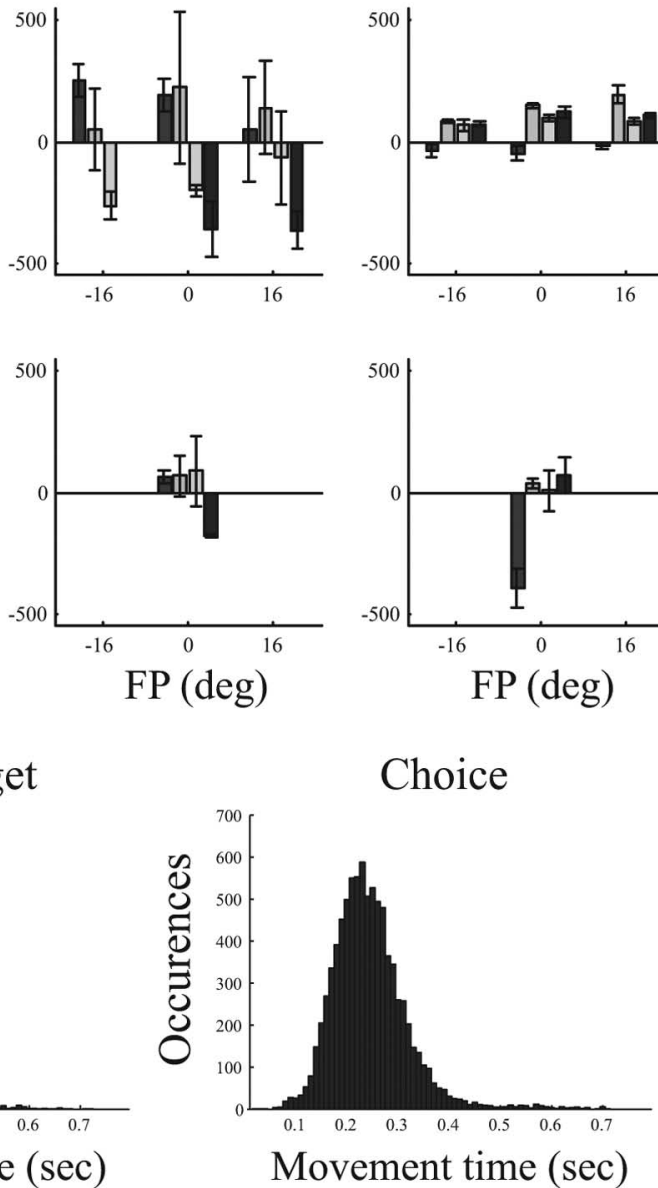

Movement time (sec)

Figure 2. Behavioral selection preference and movement times. $\boldsymbol{A}, \boldsymbol{B}$, Target selection behavior for arm reaching and saccadic erence (missing bars indicate the absence of data). Target pair orientations (I-IV) are indicated by double arrows. C, Distribution of reach movement times (FP release to target acquisition) in the single-target and the choice task (data of both animals).

to single targets to the left or right. After the presentation of the right target, the firing rate of this neuron increased strongly until the reach movement was executed. In contrast, the firing rate even decreased for movements to the left target, reflecting the fact that the right target is the preferred target of this cell. Because no delay period is present in this task, the observed activity could be visual, motor, or visuomotor. In concurrently recorded choice trials (bottom row), the left and right targets were presented with an SOA that was continually adapted between trials by a staircase procedure (see stimulus markers in the spike rasters). On individual choice trials, the animal freely selected the left (bottom left) or right (bottom right) target to receive a fixed amount of reward. In all choice trials, neural activity increased after the first, in this case the right and preferred, target was presented. This can be explained as the appearance of a visual stimulus in the response field of the neuron independent of a subsequent movement. However, the amount and persistence of increase was substantially larger for choices of the rightward (preferred) target than for leftward selections. This activity difference cannot be attributed to the visual appearance of the stimuli, because they were almost identical for either choice (for a detailed analysis, see below, Influence of SOA on choice activity). Therefore, the activ- 

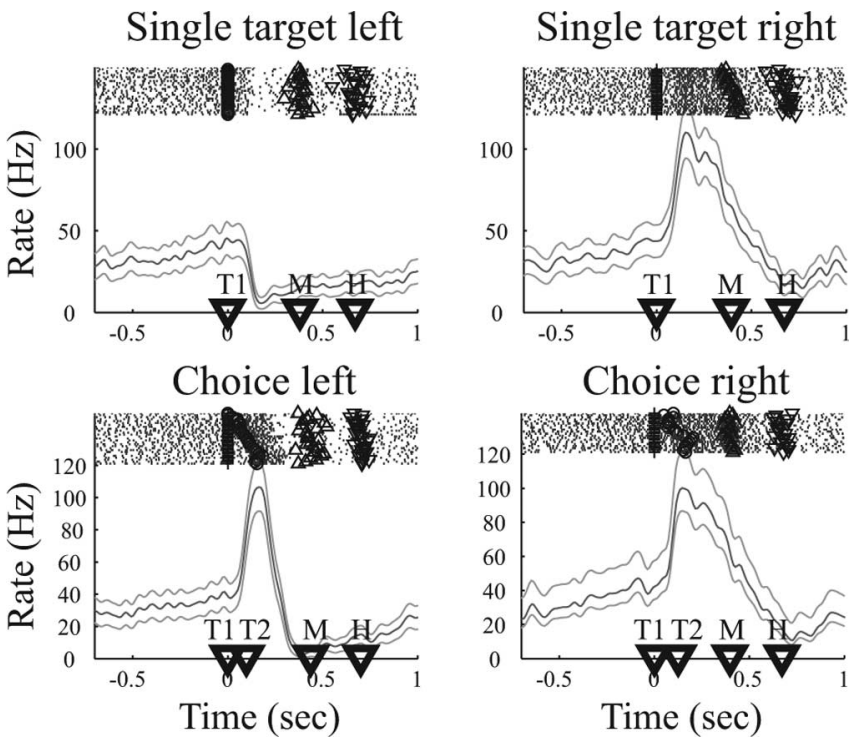

Figure 3. Example neuron during target selection for arm reaching. Top row shows neural activity for single target trials to the left or right, and bottom row shows the neural activity during choice trials, in which the animal either selected the left (left panel) or right (right panel) target. Each panel shows spike rasters at the top, with rows of dots indicating action potentials in subsequent trials. For individual trials, symbols indicate the appearance of left $(\bigcirc)$ and right $(+)$ target and the beginning $(\Delta)$ and end $(\nabla)$ of the movement. Below, the peristimulus time histogram is presented (mean rate and $95 \%$ confidence area). Time markers on the abscissa indicate the mean appearance of the first (T1) and second (T2) target and the beginning (M) and end $(\mathrm{H})$ of the movement. Trials are aligned on the appearance of $\mathrm{T} 1$.

ity difference had to be attributable to the target selection and the subsequent reach movement to the right as opposed to the left target. Clearly, this neuron showed choice-specific activity for the selection of the right reach target.

These findings were confirmed in the population activity of our dataset of 71 sequentially recorded neurons in PRR (animal C, right hemisphere, 24 cells; animal D, left hemisphere, 23 cells and right hemisphere, 24 cells). Figure $4 A$ shows the average PSTH activity in the population during the single-target and choice task for movements to the preferred target (dark curves) and the nonpreferred target (light curves). As expected, neural activity in the single-target task (left panel) was largely increased for reach movements to the preferred target, whereas activity stayed at baseline for movements to the nonpreferred target. In the choice task (right panel), a similar increase of activity was found in the population when the animal selected the preferred target. The increase started after stimulus presentation (T1, T2), reached its peak approximately at the start of the movement $(\mathrm{M})$, and returned to baseline after the movement finished $(\mathrm{H})$. For selections of the nonpreferred target, the population activity increased moderately after the stimulus presentation (T1, T2) and then quickly returned to baseline. In other words, neurons became transiently activated when a potential reach target appeared in the response field of the cell, but the cell was firing vigorously only if that stimulus was selected as a reach target.

An account of how much individual neurons discriminate between choices of the preferred and nonpreferred target is given in Figure $4 B$. The top row shows the mean firing rate for choice task with selections of the nonpreferred target $(\mathrm{CN})$ versus selections of the preferred target (CP) in the time intervals T1-T2, $\mathrm{T} 2-\mathrm{M}$, and $\mathrm{M}-\mathrm{H}$. Each point represents the activity of one neuron in one of three reach conditions (FP at $0,-16$, or $16^{\circ}$ ). The bottom row shows histograms of the firing rate difference be- tween CP and CN. Because SOA and hence the time intervals varied between trials (see Materials and Methods), firing rates were calculated for each trial and then averaged. In the time interval T1-T2 (Fig. 4B, left column), neural activity was the same for choices of the preferred and the nonpreferred target (mean difference $\pm \mathrm{SD}, d=1.1 \pm 5.8 \mathrm{~Hz} ; p=0.39, t$ test). However, during the planning period (T2-M; middle column) and during the movement execution period ( $\mathrm{M}-\mathrm{H}$; right column), neural activity was significantly increased for choices of the preferred versus the nonpreferred target (T2-M period, $d=11.6 \pm 13.7$ $\mathrm{Hz}, p<10^{-7} ; \mathrm{M}-\mathrm{H}$ period, $\left.d=17.2 \pm 17.8 \mathrm{~Hz}, p<10^{-7}\right)$. A separate analysis for the group of neurons that responded to the first target (T1-selective cells) and to the second target (T2selective cells) gave similar results. These findings demonstrate that the majority of cells reflect the selection of the reach target in addition to a visual response that is independent of the selected action.

\section{Influence of SOA on choice activity}

SOA was continually adapted between trials; therefore, the timing of the visual targets varied in the choice trials. As shown previously (Fig. 2) (Scherberger et al., 2003a), variation of SOA systematically changed the selection preference of the two targets $\mathrm{T} 1$ and T2, and the interesting question is whether any of these selection preferences are reflected in the neural activity of PRR.

To this end, we analyzed the data separately for neurons with $\mathrm{T} 1$ as their preferred target (T1-selective cells, $n=26)$ and with $\mathrm{T} 2$ as their preferred target (T2-selective cells, $n=45$ ). Figure 5, $A$ and $B$, shows the population firing rate of the T1-selective and T2-selective cells aligned to the appearance of the first (left panel) and second target (right panel). T2 cells are shown only aligned on T2. In each panel, the population activity for selections of the $\mathrm{T} 1$ target (solid curves) and the T2 target (dashed curves) is shown for three trial groups with small (red), medium (blue), and large (black) SOA. For this, trials of each neuron were distributed equally in three groups according to their SOA, and PSTHs were calculated and averaged in each group across the population.

It was found that the activity increase in the choice task depends predominantly on the animal's choice, as indicated in Figure 4 (CP vs $\mathrm{CN}$ ). Compared with this choice effect, variation of SOA produced only moderate changes in neuronal activity, indicating that the continual adaptation of SOA in our experiment was valid. However, the activity changes as a function of SOA can shed light on the underlying neuronal mechanisms of target selection, which we explore in the following.

Approximately $70 \mathrm{~ms}$ after $\mathrm{T} 1 \mathrm{was}$ presented (Fig. $5 A$, left), the population activity of the $\mathrm{T} 1$ cells rose sharply and, at time T2, had reached different activity levels depending on their SOA (right panel). Activity of T1 cells was significantly larger at time T2 for large SOAs (black curve) than for short SOAs (red curve; two-way ANOVA, $p<0.001$ ). This was true for both T1 and T2 selections. Approximately $100 \mathrm{~ms}$ after the appearance of T2, the $\mathrm{T} 1$ cell activity of $\mathrm{CP}$ and $\mathrm{CN}$ trials diverged with activity levels below $30 \mathrm{~Hz}$ for $\mathrm{CN}$ and close to $40 \mathrm{~Hz}$ for CP. Similarly, the activity of the T2 cell population increased sharply $\sim 60 \mathrm{~ms}$ after T2 (Fig. 5B). The peak increase from baseline was approximately twice as large for T2 than for T1 selection trials but showed no significant difference between trials of large and small SOAs (black and red curves; two-way ANOVA, $p=0.3$ for factor SOA). After the start of the movement (M), the activity of T1- and T2-selective cells was independent of SOA. Baseline activity was slightly higher for T2 cells (mean $\pm \mathrm{SD}, 16.9 \pm 10.1 \mathrm{~Hz}$ ) than for T1 cells (mean $\pm \mathrm{SD}, 12.7 \pm 9.7 \mathrm{~Hz})(p<0.01, t$ test $)$, which 
might reflect the monkey's bias to select the T2 target when both targets are presented simultaneously (SOA of 0 ).

The observed activity can be interpreted in terms of a race model or a mutual competition model between the T1 and T2 cell group (Cisek and Kalaska, 2002; Wang, 2002; Cisek, 2006). To illustrate this, we plotted the differential activity $\Delta f=f_{\mathrm{T} 1}-f_{\mathrm{T} 2}$ between the $\mathrm{T} 1$ and $\mathrm{T} 2$ cell populations for each SOA group (Fig. $5 C)$. Thereby, $f_{\mathrm{T} 1}$ and $f_{\mathrm{T} 2}$ denote the baseline-subtracted population activity of the $\mathrm{T} 1$ and $\mathrm{T} 2$ cell group. It is close to 0 at the beginning of the task and increases to positive values after $\mathrm{T} 1$ is presented. At the time T2 appears, $\Delta f$ is significantly larger for T1 choices than for T2 choices and is modulated within each choice group by the SOA, being strongest for large SOAs (two-way ANOVA, $p<0.001$ ). The influence of the second target T2 on the network seems to be determined by the differential activity at this time. With $\Delta f<10$ $\mathrm{Hz}$, the differential activity $\Delta f$ decreases and becomes negative as a response to $\mathrm{T} 2$, and T2 is selected as the reach target. In contrast, if $\Delta f>10 \mathrm{~Hz}, \Delta f$ shows only a small dip before rising to values above $+15 \mathrm{~Hz}$, and $\mathrm{T} 1$ is selected as the reach target. Later on in the movement period $(\mathrm{M}-\mathrm{H})$, however, $\Delta f$ seems to reflect the movement and not a stimulus feature (e.g., SOA) any more.

Together, the neural activity in PRR initially reflects the visual target stimulus, but this representation is up-modulated or down-modulated according to the preference to select the stimulus as a movement target. The representation of a second target T2 is suppressed in the population of T2-selective cells if the network is strongly active for T1. However, if T1 cells are only weakly active, the second target gets strongly encoded in the T2 cells and the first target becomes suppressed. After this selection process, the population activity represents the selected movement that is executed subsequently.

\section{Temporal evolution of choice activity}

An important aspect of target selection is the question at what time the neural activity becomes different for different choices. Figure $6 \mathrm{~A}$ shows the average firing rate of an example neuron during the single-target and the choice task with selections of the preferred (dark rasters and curve) and nonpreferred (light rasters and curve) target. In the single-target task, the firing rate for movements to the preferred and nonpreferred target became different shortly after target presentation (T1, left panel). In the choice task, the firing rates separated shortly after the second target appeared (T2, right panel; trials aligned on T2). Because T2 is the preferred target, this cell is $\mathrm{T} 2$ selective. To quantify the time when the neural activities diverge in the preferred and nonpre-
Single target
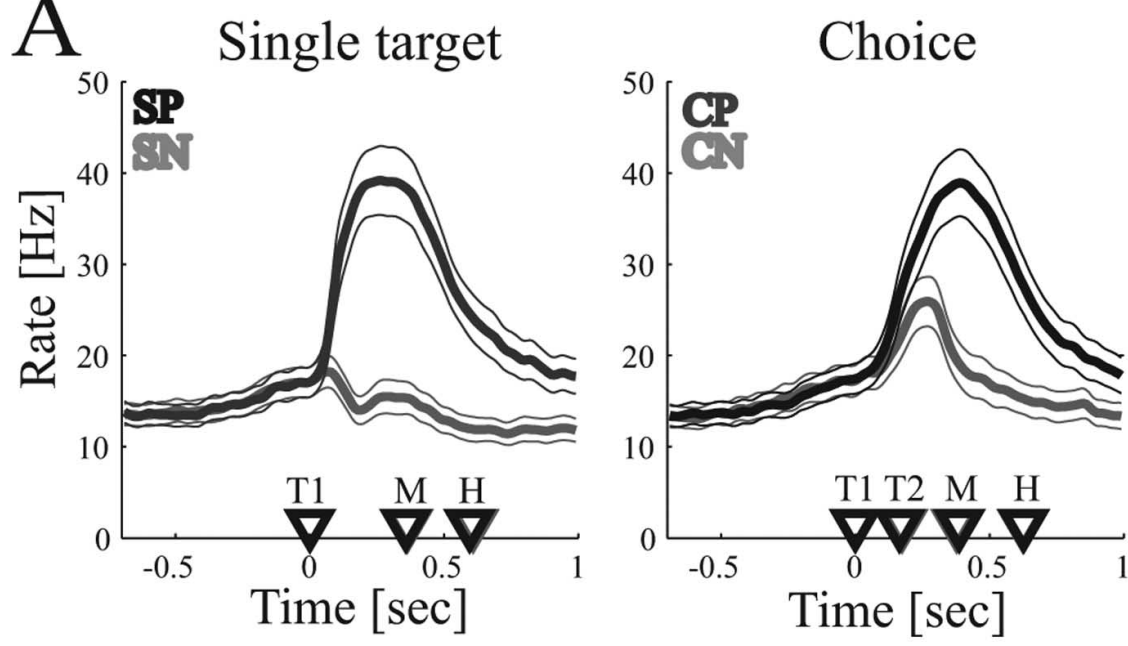
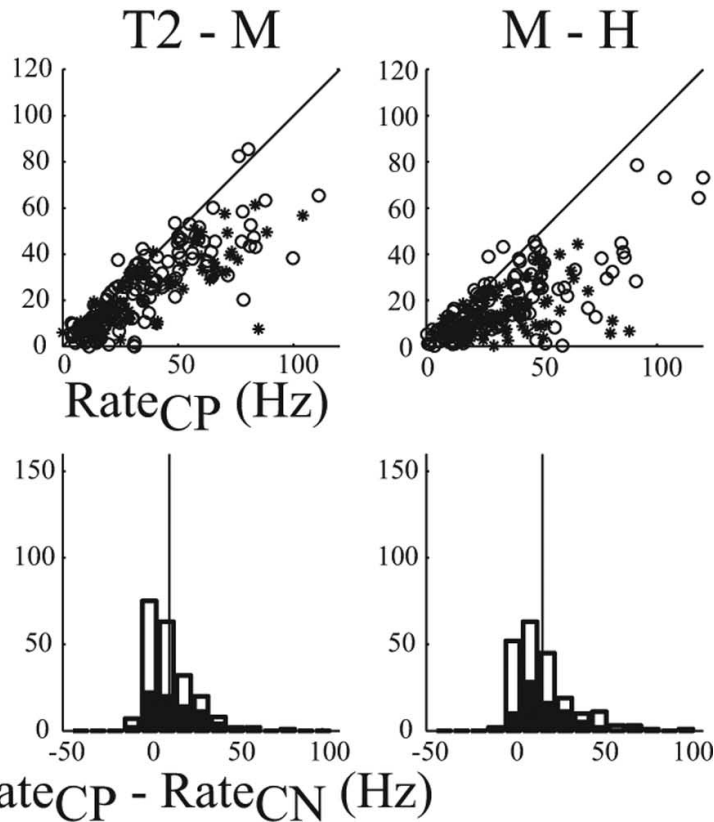

Figure 4. Population activity for reaching. $\boldsymbol{A}$, Average firing rate in the single-target (left) and the choice task (right). Curves indicate the mean firing rate (and 95\% confidence interval) for movements to the preferred (dark curve) and nonpreferred (light curve) target. Time markers indicate the mean appearance of the first (T1) and second (T2) target and the beginning (M) and end 2-selective cells in each of the three reach conditions: $\mathrm{FP}$ of $0,-16$, and $16^{\circ}$. Top row, Scatter plots; Bottom row, Histograms of the activity difference between CP and CN (black bars, T1 cells; white bars, T2 cells). Vertical line indicates the mean.

ferred target groups, we performed an ROC analysis (Fig. 6B). Each point on the ROC graph (solid curve) gives the level of predictability (in bits of information) an ideal observer would have to predict the selection of the animal (preferred vs nonpreferred target) when evaluating the firing rate in the most recent 200 ms time interval (see Materials and Methods). The ROC predictability in the single-target task and the choice task is initially at chance ( 0.5 bit) and then increases to 1 bit after target presentation. We defined the ts as the time after stimulus presentation (T1 or T2) when the ROC predictability consistently exceeds the 95\% confidence limit for chance (dotted lines) (see Materials and Methods). We found ts $=91 \mathrm{~ms}$ in the single target task and ts $=64 \mathrm{~ms}$ in the choice task (vertical lines), which was $233 \mathrm{~ms}$ before the movement started in the single target task and $112 \mathrm{~ms}$ before movement onset in the choice task. 

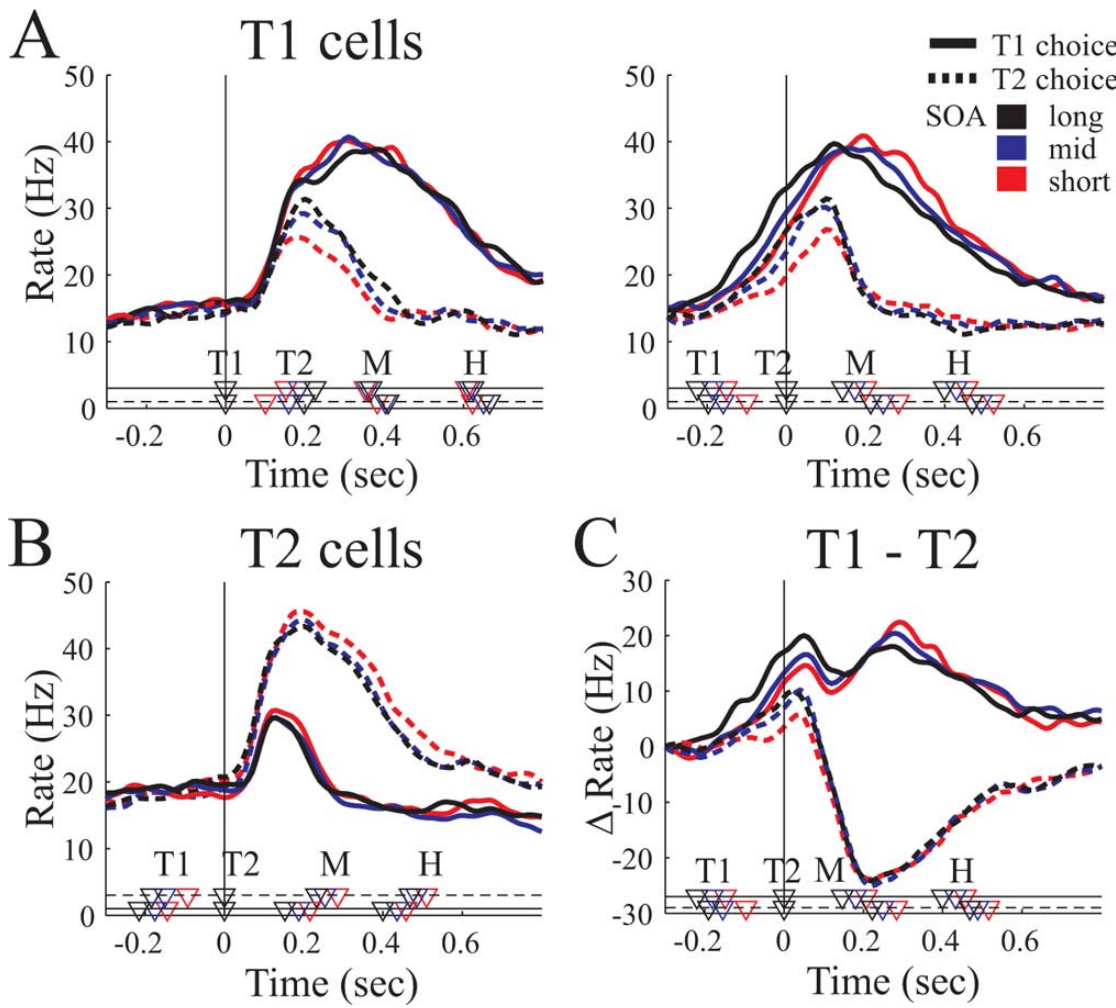

Figure 5. Influence of SOA on choice activity. $\boldsymbol{A}, \boldsymbol{B}$, Population activity of T1-selective cells aligned on T1 (left panel) and T2 (right panel) and of T2-selective cells aligned on T2. In each panel, mean firing rate and behavioral markers are shown separately for selecting the first target (solid lines) or the second target (dotted lines) and for trials with short (red), medium (blue), or long (black) SOAs. C, Differential activity $\Delta f=f_{\mathrm{T} 1}-f_{\mathrm{T} 2}$ between the $\mathrm{T} 1$ and $\mathrm{T} 2$ cell population for selections of T1 (solid lines) and $\mathrm{T} 2$ (dotted lines) and the three SOA groups (different colors). Curves start at 0 because baseline activity was subtracted. Markers at the bottom indicate behavioral times for T1 choices (on solid line) and T2 choices (on dotted line) and the three SOA groups (different colors). Marker labels as in Figure 3. Vertical lines indicate alignment.

These findings were confirmed in our dataset of 71 neurons, which we present separately for the T1-selective $(n=26)$ and T2-selective $(n=45)$ cells. Figure 7, $A$ and $B$, top row, shows the averaged PSTH of the neural population in the single target and the choice task for reach movements to the preferred target (dark curves) and nonpreferred target (light curves) of each cell. Choice trials of T2 cells are aligned to T2, whereas all other trials are aligned on T1. For better comparison with a later analysis (saccade task, see below), we present here only the straight-ahead reach condition (FP of 0 ), but similar results were obtained for all reach conditions ( $\mathrm{FP}$ of $-16,0,16^{\circ}$ ). Bottom panels in Figure $7, A$ and $B$, show the mean ROC predictability (black curve) and $95 \%$ confidence limits (gray area). In the single-target task (left panel), mean ROC predictability reached levels significantly above chance $110 \mathrm{~ms}$ (T1 cells) and $95 \mathrm{~ms}$ (T2 cells) after target presentation (vertical bars). In the choice task (right panels), the mean ROC curve exceeded chance $82 \mathrm{~ms}$ after T1 (T1 cells) and $126 \mathrm{~ms}$ after T2 (T2 cells). These times preceded the reach movement onset by $268 \mathrm{~ms}$ (T1 cells) and $287 \mathrm{~ms}$ (T2 cells) in the single-target task and by $329 \mathrm{~ms}$ (T1 cells) and $109 \mathrm{~ms}$ (T2 cells) in the choice task.

In comparison, the mean $\pm \mathrm{SD}$ reaction time in the delayed reach task (time from "Go" signal to movement start) was $161 \pm$ $31 \mathrm{~ms}$ for T1 cells and $155 \pm 39 \mathrm{~ms}$ for T2 cells. Assuming a minimal perceptual latency of $40 \mathrm{~ms}$ for the Go signal (Bair et al., 2002; Bisley et al., 2004), the movement latency (from movement initiation to FP release) in the delayed reach task can be estimated as $\sim 120 \mathrm{~ms}$ or less. This is clearly faster than the latencies between significant predictability and movement onset in the single-target and choice task, except for T2 cells in the choice task, in which the latencies are comparable. These findings demonstrate that the population activity in PRR reflects the reach targets choice and cannot be regarded simply as a motor command.

Individually, 67 cells (94\%) had a finite separation time (ts $<\infty$ ) in the singletarget task, whereas the ROC curve did not significantly exceed chance (ts $=\infty$ ) in four cells $(5.6 \%)$. In the choice task, 61 of 71 cells $(86 \%)$ had a finite separation time. A histogram of the separation times in the choice task is given in Figure $7 C$, separately for T1 cells (relative to T1) and T2 cells (relative to T2). Together, the temporal evolution of reach choice activity in PRR was compatible with previous studies of free-choice activity in LIP, in which the decision signal for saccade target selections also separated $\sim 100-125 \mathrm{~ms}$ after target onset (Coe et al., 2002; Sugrue et al., 2004).

\section{Saccade activity in PRR}

How movement specific is the neural activity in PRR? To address this question with respect to target selection, we recorded PRR activity also during the selection of saccade targets for all cells of the dataset. A single-target task and a choice task for saccade movements were run randomly interleaved with reach target selections. Figure 8 shows the population results of the single-target and the choice task during saccade target selection. As expected from previous work (Snyder et al., 2000; Scherberger et al., 2005), spiking activity in PRR increased when a saccade target appeared in the preferred direction of a cell but was not elevated from baseline when a saccade target appeared in the opposite (nonpreferred) direction (Fig. 8A, left). This might reflect a visual response or, because reaches and saccades were randomly interleaved, an initial plan to make a reach movement instead of a saccade (Snyder et al., 2000; Calton et al., 2002). In the saccade choice task, however, the population activity increased almost independently of the choice (right panel). Furthermore, the population peak activity in the saccade single-target and choice task [single target to the preferred target (SP), $29.5 \mathrm{~Hz}$; CP, 27.5 Hz] was substantially reduced compared with the corresponding reach tasks (SP, $39.2 \mathrm{~Hz}$; CP, 41.4 Hz) (Fig. 7). In other words, our findings are consistent with the hypothesis that PRR neurons transiently represent visual stimuli that appear in the response field of the cell but do not directly represent target selection and movement planning for saccades.

To quantify these findings, we performed the same ROC analysis for the saccade tasks as for reaches (Fig. 7). In the saccade single-target task, the mean ROC predictability exceeded change level ( 0.5 bit $) \sim 118 \mathrm{~ms}$ after target presentation and reached a peak of 0.77 bit at approximately saccade execution (300 ms) (Fig. $8 \mathrm{~B}$, left). In the saccade choice task (right panel), however, this increase was almost completely absent. The average ROC predictability increased after target presentation only very gradually and led to a late and small peak of 0.60 bit after the saccade had already been finished (380 ms after target presentation). 

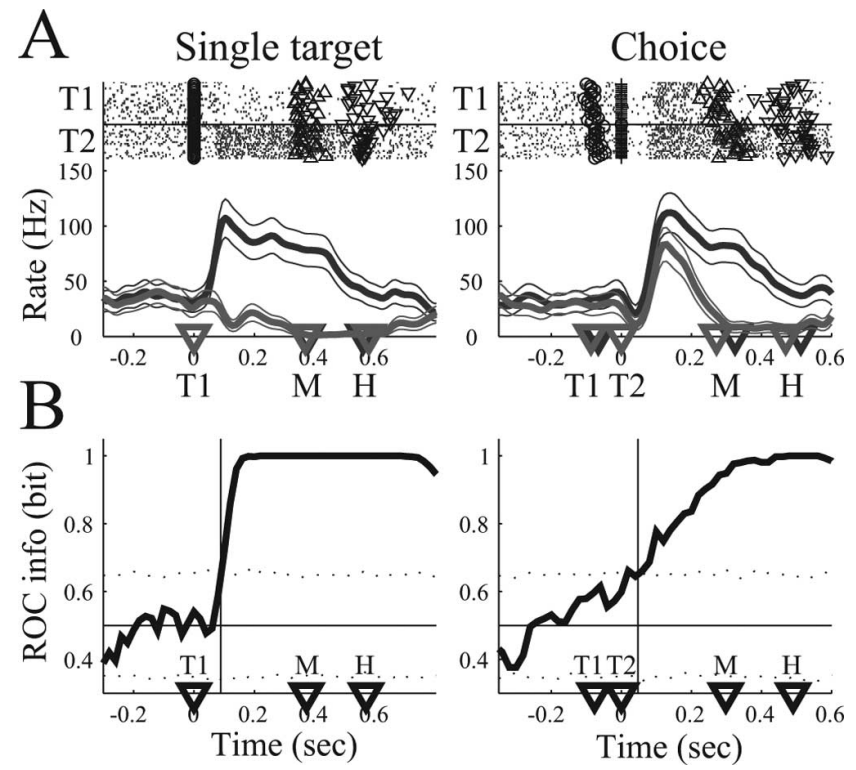

Figure 6. ROC analysis of an example neuron (T2 cell). $\boldsymbol{A}$, Spike rasters and PSTH for singletarget (left column) and the choice (right column) task. Trials to the preferred target (T2, dark) and nonpreferred target ( $\mathrm{T} 1$, light) are presented separately. Activity in the choice task is aligned on the second target (T2). The neuron is responsive to T2. B, ROC information graph (thick curve) indicating the level of predictability an ideal observer would have in predicting the selection of the animal (preferred or nonpreferred target) at each moment in time when evaluating the neural activity in the most recent $200 \mathrm{~ms}$ time interval. Horizontal line, Chance level ( 0.5 bit). Thin vertical line, Separation time, defined as the time when the ROC curve consistently exceeds the $95 \%$ confidence limit for chance (dotted lines) (see Materials and Methods). Other conventions as in Figure 3.

In the saccade single-target task, ts was finite in 57 of 71 cells $(80 \%)($ mean \pm SD ts, $175 \pm 141 \mathrm{~ms})$, whereas ts was infinite in 14 cells $(20 \%)$. In the saccade choice task, however, only 39 cells (55\%) had an ROC predictability above chance (mean \pm SD ts, $160 \pm 184 \mathrm{~ms})$, whereas ts of 32 cells $(45 \%)$ was infinite. The distribution of ts in the choice task is given in Figure $8 C$, separately for T1- and T2-selective cells.

To compare ts of individual cells in the reach and saccade task with a simple measure, we classified neurons as anticipatory (A) if ts $<\mathrm{T} 1$, planning-related (P) if $\mathrm{T} 1 \leq \mathrm{ts}<\mathrm{M}$, movement-related (M) if $\mathrm{M} \leq \mathrm{ts}<\mathrm{H}$, and indifferent if ts $\geq \mathrm{H}$ or infinite. This classification was done for the single-target and the choice task as well as for reaches and saccades (Fig. $8 D, E$ ). In the single-target task, 49 cells (70\%) were task selective (classes A, P, or M) for both reaches and saccades, whereas 15 cells $(21 \%)$ were task selective only for reaches, 4 cells (6\%) only for saccades, and 3 cells (4\%) for neither one. Activity in the choice task, however, was largely indifferent for saccades: 30 cells $(42 \%)$ were task selective for reaches and saccades, 27 cells (38\%) for reaches only, 2 cells (3\%) for saccades only, and 12 cells $(17 \%)$ for neither reaches nor saccades.

Our findings provide additional evidence that reach and saccade movements are encoded differently in PRR. As expected, visual stimuli are represented in PRR in reach as well as saccade tasks. This was observed in the target-selective response in the single target task and the common response in the choice task for reaches and saccades. However, with respect to target selection, PRR predominantly represents reach movements: 57 cells (80\%) were target selective for reaches (classes A, P, or M), whereas only 32 cells $(45 \%)$ were target selective for saccades. These results highlight the action-specific role of PRR for the generation of reach movements and in particular for reach target selection.

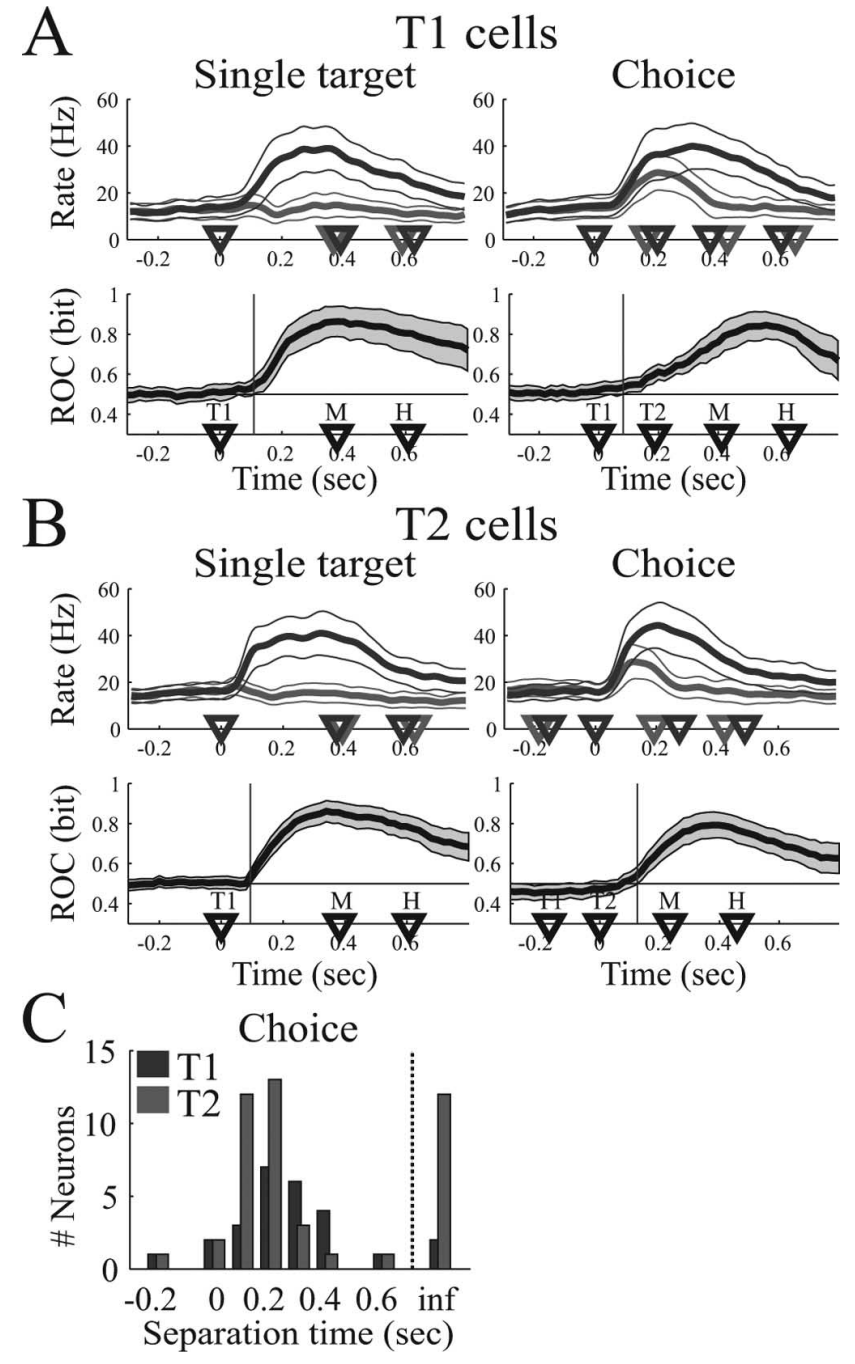

Figure 7. Temporal evolution of choice activity. $\boldsymbol{A}$, Analysis of $\mathrm{T} 1$ cells $(n=26)$. $\boldsymbol{B}$, Analysis of T2 cells ( $n=45$ ). In $\boldsymbol{A}$ and $\boldsymbol{B}$, the top row shows the mean firing rate (and $95 \%$ confidence limit) in the single-target task (left side) and the choice task (right side) for reach movements to the preferred (dark curve) and nonpreferred (light curve) target. Bottom row shows the mean ROC predictability (thick curve) and $95 \%$ confidence limit (gray area). Vertical line, Time when mean ROC curve significantly exceeds chance $(p<0.05)$. Choice trials are aligned on T1 for T1 cells and on T2 for T2 cells. C, Histogram of separation time of T1 cells (dark bars) and T2 cells (light bars). inf, ts $=\infty$. Separation times are presented relative to alignment (T1 for T1 cells, T2 for T2 cells).

\section{Eye position gain fields}

It has been shown that neurons in PRR encode reach movements with respect to where the eye is looking, i.e., in a retinotopic reference frame, and that the activity of these neurons is gain modulated by the eye position (Batista et al., 1999; Buneo et al., 2002). Such gain modulation of neural activity is expected when the FP position is changed, which we tested here for the singletarget and the choice task. Figure 9 shows an example neuron during the reach task with the FP to the left, straight ahead, and right (different columns) and the four tasks: SP (in this case left target), $\mathrm{CP}$ or $\mathrm{CN}$ target, and single target to the nonpreferred target (SN). Each panel depicts individual spike rasters on top of the peristimulus time histogram. When comparing SP with SN and $\mathrm{CP}$ with $\mathrm{CN}$ trials, a strong preference for the preferred (left) target is apparent for each FP.

Furthermore, in each task with activity above baseline (SP, $\mathrm{CP}$, and $\mathrm{CN}$ ), neural activity decreased the more the FP was 

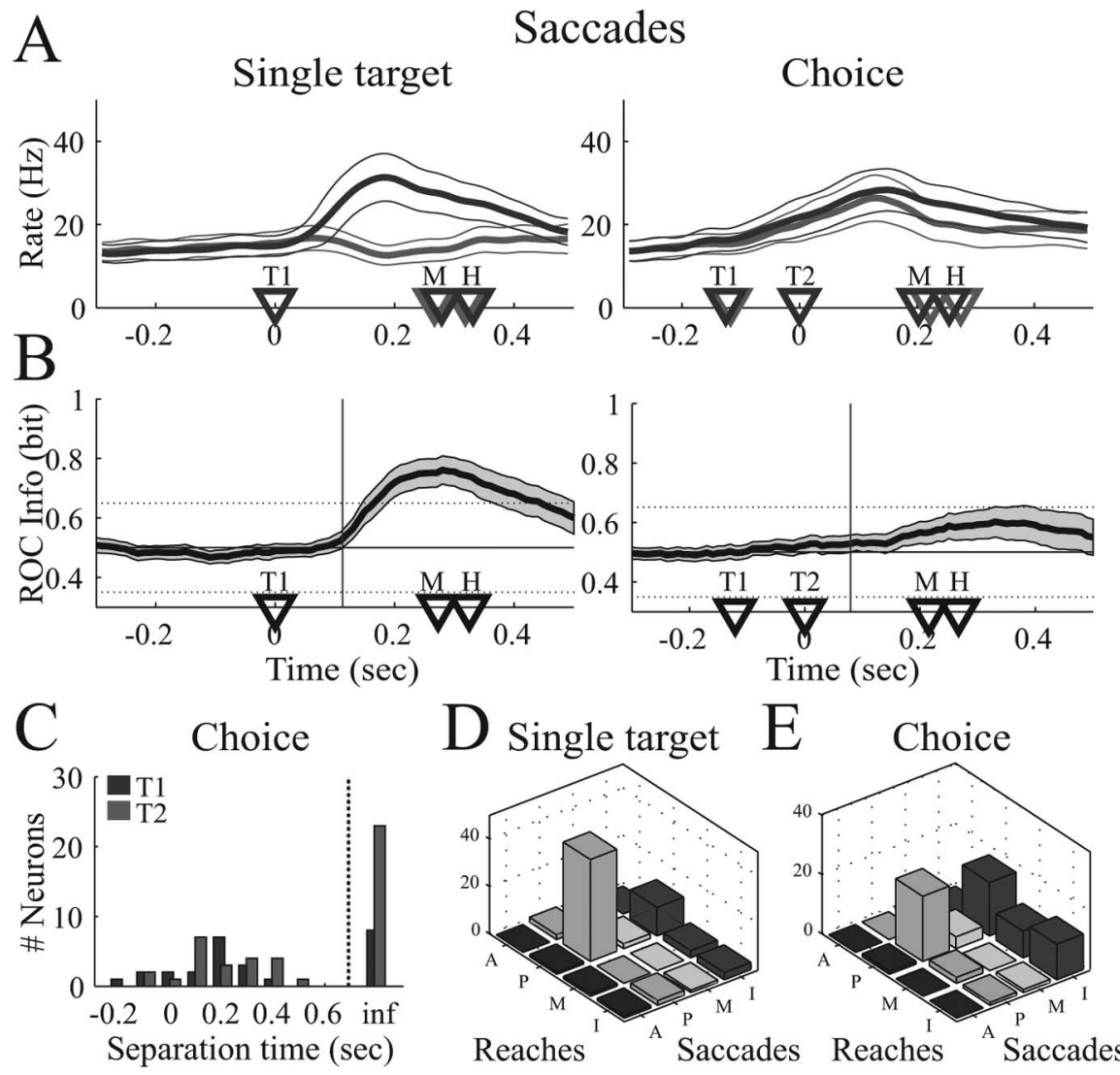

Figure 8. Population activity in the saccade task. $\boldsymbol{A}$, Mean firing rate for saccades to the preferred (dark curve) and nonpreferred (light curve) target. $\boldsymbol{B}$, Mean ROC predictability of the population. Vertical line, Time when mean ROC curve significantly exceeds chance $(p<0.05)$. C, Histogram of separation time in the saccade choice task. $\boldsymbol{D}$, Cell classification for reaches and saccades in the single-target and the choice task. Cells are classified in four groups: $\mathrm{A}$, anticipatory (ts $<\mathrm{T} 1$ ); $\mathrm{P}$, planning related (T1 $\leq$ ts $<\mathrm{M}$ ); $M$, movement related $(M \leq t s<H)$; and $\mathrm{I}$, indifferent (ts $\geq H$ or $t s=\infty$ ).

shifted to the right, indicating a gain modulation of the neural activity by the eye position (FP). To quantify this gain modulation by the FP, we defined a gain coefficient as gc $=\left(f_{P}-f_{N}\right) /\left(f_{P}\right.$ $\left.+f_{N}\right)$, where $f_{P}$ and $f_{N}$ denote the mean firing rate in the time interval $\mathrm{T} 1-\mathrm{H}$ with the $\mathrm{FP}$ shifted horizontally by $16^{\circ}$ from straight ahead toward the preferred $\left(f_{P}\right)$ or nonpreferred $\left(f_{N}\right)$ target (see Materials and Methods). By this definition, the coefficient gc ranges between -1 and 1 , and positive (or negative) values denote an increase (or decrease) in firing rate as the FP is shifted horizontally toward the preferred target of the cell. In contrast, gc $=0$ indicates no change of activity. For this neuron, we found a gc of $0.18^{\star}(\mathrm{SP}), 0.23^{\star}(\mathrm{CP}), 0.33^{\star}(\mathrm{CN})$, and 0.03 $(\mathrm{SN})\left({ }^{*} p<0.05, t\right.$ test $)$, indicating a consistent gain effect toward the preferred (left) target in the single-target and the choice task.

The same analysis was performed with 59 of 71 neurons that had a nonvertical preferred orientation (II-IV) (Fig. $1 B$ ). The mean gc in the population (Fig. 10A) was statistically 0 for SP (left panel) $(p=0.67)$ as well as for CP (right panel) $(p=0.47)$. The number of cells with a significantly negative, 0 , and significantly positive gc was 16, 33, and 10 cells for SP and 16,34, and 9 cells for $\mathrm{CP}(p<0.05, t$ test $)$. More importantly, the gain coefficient in SP and $\mathrm{CP}$ trials were strongly correlated $\left(r^{2}=0.67\right)$ (Fig. $\left.10 \mathrm{~B}\right)$. The regression slope of gc for $\mathrm{CP}$ versus SP was 0.89 and was not significantly different from unity $(p=0.56)$. Similar findings were obtained for the nonpreferred target conditions $\mathrm{CN}$ and $\mathrm{SN}$ (mean gc for SN of, 0.03, $p=0.41$; and for $\mathrm{CN}$ of $0.00, p=0.99$; regression slope gc_CN versus gc_SN of $0.68, p=0.21, r^{2}=0.59$ ) and when gc was calculated with respect to the left and right target instead of the preferred and nonpreferred target (data not shown). These findings demonstrate the existence of eye-position gain fields in PRR during reach target selection and show that they are identical to the corresponding gain fields in single-target trials.

As shown above (Fig. 2), the preference of the animal for a right target decreases the more the FP is shifted to the right, which corresponds to an increase in BTD. To test the hypothesis that the gain modulation of individual neurons correlates with the change of selection preference, we plotted the gain coefficient gc versus the difference of BTD between the left and right FP condition (Fig. 10C). It was found that gc is uncorrelated with changes in selection preference attributable to the FP $\left(r^{2}=0.007 ; p=0.53\right)$.

Together, gain field effects were independent of the preferred direction of the cell, identical in the single-target and the choice task, and did not correlate with changes of the animal's selection preference. These findings do not support the hypothesis that eye-position gain fields are directly related to target selection in PRR. However, they are in agreement with the notion of a more general role of eye position gain fields for coordinate transformation and sensorimotor processing.

\section{Discussion}

In this paper, we investigated the activity of PRR neurons during target selection for arm reaching in a free-choice paradigm. Using an adaptive staircase procedure to control the SOA of two visually presented targets, the animal's preference was balanced such that both targets were selected equally often (Fig. 1) and independent of biasing effects such as the target orientation and the FP in space (Fig. 2).

Single-unit activity in PRR was strongly linked to the target selection of the animal. When two targets were presented, one inside and one outside of the response field of the cell, neurons produced a vigorous response when the target in the response field was selected but only a minor response when the target outside of the response field was chosen (Fig. 3). These differences were highly significant in the population (Fig. 4), demonstrating that signals in PRR are not merely driven by the visual input or motor output but reflect the target selection process for intended reach movements. Neural activity was strongly linked to the choice of the animal, and the influence of SOA was found to be compatible with a race model or mutual competition model of target selection (Fig. 5). Furthermore, an ROC analysis of T1- and T2-selective cells showed that PRR activity discriminated between the two targets well before the movement started (Figs. 6, 7).

Target selection of saccades was only weakly represented in PRR (Fig. 8). Although visual stimuli in the response field of the cell often activated PRR cells, most neurons were indifferent for saccade target selection. Moreover, task-sensitive cells for saccades were also sensitive for reaches. The latter suggests a role of 
these cells for eye-hand coordination, which becomes important for the guidance of arm movements under more natural conditions (Land et al., 1999; Neggers and Bekkering, 2000; Johansson et al., 2001; Pesaran and Andersen, 2003).

Finally, neural activity of many neurons was gain modulated by the $\mathrm{FP}$ in space. Such gain modulations were identical in the single-target and choice task and did not directly influence the target selection process in our task (Figs. 9, 10), suggesting that eye-position gain fields play a more general role for sensorimotor processing, such as coordinate transformation (Batista et al., 1999; Buneo et al., 2002).

\section{Neural activity in PRR}

Our findings are in agreement with previous clinical, electrophysiological, and imaging studies showing that the PPC is neither purely visual nor motor but intimately involved in the transformation of sensory signals for actions (Balint, 1909; Mountcastle et al., 1975; Andersen et al., 1985; Goldberg et al., 1990; Kalaska, 1996; Rushworth et al., 2001; Simon et al., 2002). In the macaque monkey, the role of PRR for the transformation of visual signals to reach commands has been explored exten-

sively using a delayed reach task (Snyder et al., 1997, 1998; Batista et al., 1999; Buneo et al., 2002). It was demonstrated that many PRR cells are active in the planning period of the reach task in addition to responses in the visual and motor periods. This corresponds to our finding that PRR cells reflect the visual stimulus at the beginning of the trial and the movement execution at the end of the trial. Similar observations have been made in other parts of the parietal cortex, i.e., LIP for the generation of eye movements (Gnadt and Andersen, 1988; Bracewell et al., 1996; Colby et al., 1996; Mazzoni et al., 1996) and in the anterior parietal area for hand grasping (Sakata et al., 1995; Murata et al., 2000). Furthermore, it has been shown that PRR is specifically involved in the planning of reach movements but not of saccades, whereas the neighboring area LIP is intimately related to the generation of eye movements but not of reaches (Snyder et al., 1997, 1998; Quian-Quiroga et al., 2006). This reach movement specificity of PRR was also observed for target selection in our data.

The coordinate frame in which reach and saccade movements are planned is eye centered in both PRR and LIP, suggesting a unified framework of space representation in the PPC (Batista et al., 1999; Buneo et al., 2002). The activity of these neurons is gain modulated by the eye and arm position in space, and these eye- or arm-position gain fields implement a distributed representation of space (Andersen et al., 1985, 1990; Buneo et al., 2002). This allows target coordinates to be read out in multiple coordinate frames at subsequent processing stages (Zipser and Andersen, 1988; Salinas and Abbott, 1995; Andersen, 1997; Pouget and Snyder, 2000; Xing and Andersen, 2000). Our finding of identical eye-position gain fields in the single-target and choice task adds additional support for this role in coordinate transformation.

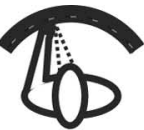

$\mathrm{FP}=-16 \mathrm{deg}$
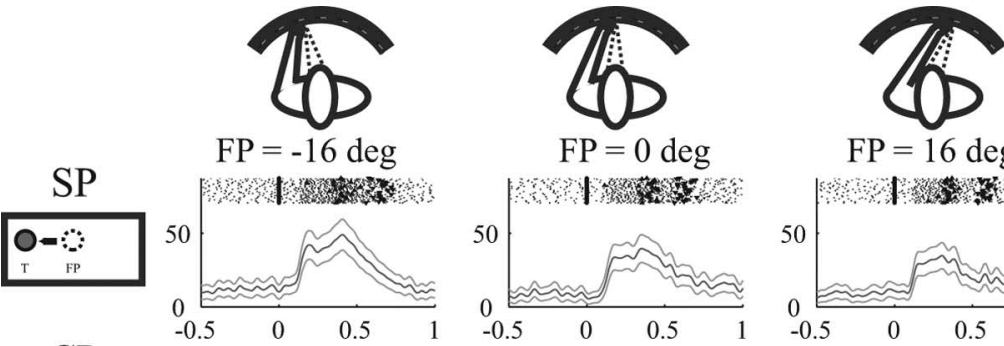

$\mathrm{gc}$
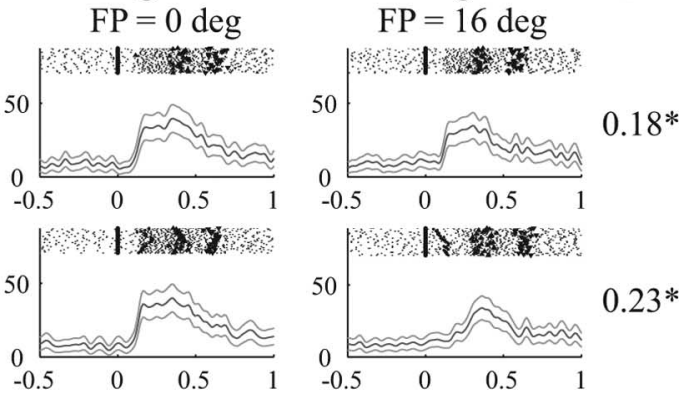

$0.23 *$
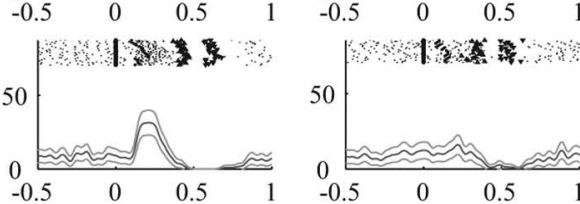

$0.33^{*}$
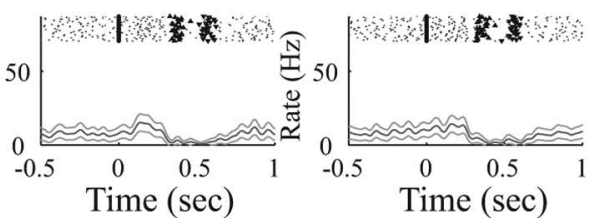

\section{Decision making}

We balanced the selection of leftward and rightward choices by adapting the SOA of the presented targets, while the amount and frequency of reward was kept constant. Our task therefore differs from several previous studies investigating decision making. First, target selection does not depend on the detection of an external cue that determines the correct response for a particular trial (Shadlen and Newsome, 1996; Gold and Shadlen, 2000). Instead, we used a free-choice task with salient visual stimuli and all choices equally valid. Second, target selection in our task does not depend on the amount of reward the animal can expect to receive for executing a particular behavior. The expected value of a trial, defined as reward probability $\times$ reward size, was constant and identical for all selections, whereas in several other studies, the expected value was systematically varied (Platt and Glimcher, 1999; Coe et al., 2002; Glimcher, 2003; Barraclough et al., 2004; Sugrue et al., 2004). In fact, the design of our experiment was such that any remaining preference for a particular target (e.g., attributable to the FP location or which arm was moving) was counterbalanced by the SOA. This leaves the subject at a "choice equilibrium" in which all selections are equally valid (Nash, 1950; Glimcher, 2003). Under these conditions (absence of external choice cues and equal expected value for all choices in a given trial), the observed difference of neural activity between preferred and nonpreferred targets must reflect an internal, as opposed to external, selection signal.

\section{Possible interpretations}

The observed difference of neural activity for selecting T1 or T2 could either reflect a target selection signal or an arm movement plan without being part of the selection process. These two possibilities cannot be easily disentangled. Our timing analysis shows 

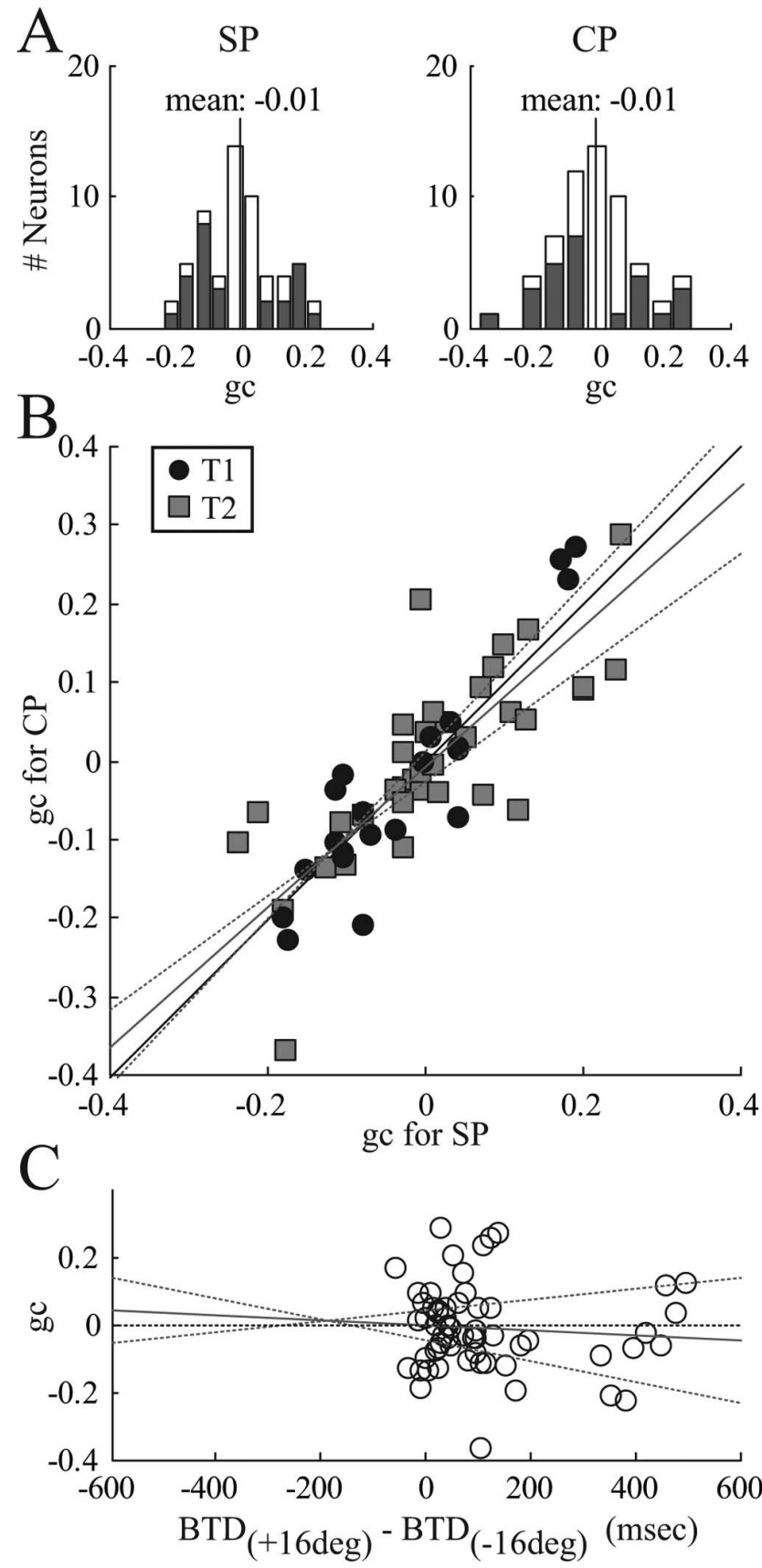

Figure 10. Population results of gain field analysis. All neurons with nonvertical orientation are included $(n=59)$. $\boldsymbol{A}$, Histogram of gain coefficients ( $\mathrm{gc}$ ) in the single-target task to the preferred target (SP, left) and in the choice task with selection of the preferred target ( $(\mathrm{CP}$, right). Cells with gc significantly different from 0 are shown in dark $(p<0.05)$. Vertical line indicates the mean gc. $B$, Scatter plot of $g c$ in the CP task versus the SP task. Circles, T1 cells; squares, T2 cells. Thin solid line, Unity line; gray and dotted lines, linear regression and $95 \%$ confidence limits (not significantly different from unity). C, Regression of gc versus the BTD difference between left and right FP conditions. Circles, Individual neurons. Thin solid line, 0 line. Gray and dotted lines, Linear regression and 95\% confidence limits (no significant correlation).

an early representation of preference and choice, which is observed for T1-selective cells before and for T2-selective cells right after the second target appears. It is therefore unlikely that PRR activity reflects only the motor command and is unrelated to the target selection process. This raises the question of what neuronal mechanisms underlie target selection in PRR.

Neural activity in PRR could be modulated by (1) an internal signal reflecting an a priori choice preference and (2) by the ap- pearance of the two targets. Depending on the choice preference, the appearance of the first target will induce either a strong or a weak response in PRR. This has been observed in the neural activity of the T1 cells. Their activity can be interpreted as the emergence of a movement plan to reach to T1. Similarly, the appearance of the second target induces a movement plan in PRR for reaching to T2, which is also modulated by the choice. The observed activity of the T2 cells can be interpreted as the emergence of such a second movement plan in PRR. Both movement plans could temporarily coexist before a selection mechanism would lead to the elimination of the weaker and the execution of the stronger movement plan. For this competition, the timing of the second target (SOA) is important, because the further the plan to move to T1 has evolved, the harder it will be for T2 to compete against the existing plan to move to T1.

This view borrows from a "race model" that has been proposed for free-choice tasks in decision making (Cisek and Kalaska, 2002, 2005; Coe et al., 2002) and for countermanding paradigms (Logan and Cowan, 1984; Hanes and Schall, 1995; Kalaska and Crammond, 1995; Cabel et al., 2000). Moreover, our findings are also compatible with a recent mutual competition model, in which the T1 and T2 cell activity mutually inhibit each other and the selection is determined by the balance of the two cell groups without the assumption of an explicit threshold (Cisek, 2006). PRR has all of the ingredients to integrate topdown (choice preferences) and bottom-up influences (visual stimuli) for the selection of reach targets, and our findings support this view. However, the existence of intimate connections with other, in particular premotor and parietal, areas that have also been shown to reflect decision signals (Coe et al., 2002; Cisek and Kalaska, 2005) implies that decision making takes place in a distributed network. Our findings suggest that PRR is part of a decision network for reach movements and that several decisionmaking networks exist for different types of actions.

\section{References}

Andersen RA (1987) The role of the inferior parietal lobule in spatial perception and visual-motor integration. In: Handbook of physiology: the nervous system. Higher functions of the brain (Plum F, Mountcastle VB, Geiger SR, eds), pp 483-518. Bethesda, MD: American Physiological Society.

Andersen RA (1997) Multimodal integration for the representation of space in the posterior parietal cortex. Philos Trans R Soc Lond B Biol Sci 352:1421-1428.

Andersen RA, Essick GK, Siegel RM (1985) Encoding of spatial location by posterior parietal neurons. Science 230:456-458.

Andersen RA, Bracewell RM, Barash S, Gnadt JW, Fogassi L (1990) Eye position effects on visual, memory, and saccade-related activity in areas lip and 7a of macaque. J Neurosci 10:1176-1196.

Bair W, Cavanaugh JR, Smith MA, Movshon JA (2002) The timing of response onset and offset in macaque visual neurons. J Neurosci 22:3189-3205.

Balint R (1909) Seelenlähmung des "Schauens", optische Ataxie, räumliche Störung der Aufmerksamkeit. Monatsschr Psychiatr Neurol 25:51-81.

Barraclough DJ, Conroy ML, Lee D (2004) Prefrontal cortex and decision making in a mixed-strategy game. Nat Neurosci 7:404-410.

Batista AP, Buneo CA, Snyder LH, Andersen RA (1999) Reach plans in eyecentered coordinates. Science 285:257-260.

Bisley JW, Krishna BS, Goldberg ME (2004) A rapid and precise onresponse in posterior parietal cortex. J Neurosci 24:1833-1838.

Bracewell RM, Mazzoni P, Barash S, Andersen RA (1996) Motor intention activity in the macaque's lateral intraparietal area. II. Changes of motor plan. J Neurophysiol 76:1457-1464.

Britten KH, Shadlen MN, Newsome WT, Movshon JA (1992) The analysis of visual motion: a comparison of neuronal and psychophysical performance. J Neurosci 12:4745-4765. 
Buneo CA, Jarvis MR, Batista AP, Andersen RA (2002) Direct visuomotor transformations for reaching. Nature 416:632-636.

Cabel DW, Armstrong IT, Reingold E, Munoz DP (2000) Control of saccade initiation in a countermanding task using visual and auditory stop signals. Exp Brain Res 133:431-441.

Calton JL, Dickinson AR, Snyder LH (2002) Non-spatial, motor-specific activation in posterior parietal cortex. Nat Neurosci 5:580-588.

Cisek P (2006) Integrated neural processes for defining potential actions and deciding between them: a computational model. J Neurosci 26:9761-9770.

Cisek P, Kalaska JF (2002) Simultaneous encoding of multiple potential reach directions in dorsal premotor cortex. J Neurophysiol 87:1149-1154.

Cisek P, Kalaska JF (2005) Neural correlates of reaching decisions in dorsal premotor cortex: specification of multiple direction choices and final selection of action. Neuron 45:801-814.

Coe B, Tomihara K, Matsuzawa M, Hikosaka O (2002) Visual and anticipatory bias in three cortical eye fields of the monkey during an adaptive decision-making task. J Neurosci 22:5081-5090.

Colby CL, Duhamel JR, Goldberg ME (1996) Visual, presaccadic, and cognitive activation of single neurons in monkey lateral intraparietal area. J Neurophysiol 76:2841-2852.

Connolly JD, Goodale MA, Desouza JF, Menon RS, Vilis T (2000) A comparison of frontoparietal fMRI activation during anti-saccades and antipointing. J Neurophysiol 84:1645-1655.

Fischer NI (1993) Statistical analysis of circular data. Cambridge, UK: Cambridge UP.

Gescheider GA (1997) Psychophysics: the fundamentals, Ed 3. Mahwah, NJ: Erlbaum.

Geshwind N, Damasio AR (1985) Apraxia. In: Handbook of clinical neurology (Vinken PJ, Bruyn GW, Klawans HL, eds), pp 423-432. Amsterdam: Elsevier.

Glimcher PW (2003) Decisons, uncertainty, and the brain. The science of neuroeconomics. Cambridge, MA: MIT.

Gnadt JW, Andersen RA (1988) Memory related motor planning activity in posterior parietal cortex of macaque. Exp Brain Res 70:216-220.

Gold JI, Shadlen MN (2000) Representation of a perceptual decision in developing oculomotor commands. Nature 404:390-394.

Goldberg ME, Colby CL, Duhamel JR (1990) Representation of visuomotor space in the parietal lobe of the monkey. Cold Spring Harb Symp Quant Biol 55:729-739.

Goodale MA, Milner AD (1992) Separate visual pathways for perception and action. Trends Neurosci 15:20-25.

Green DM, Swets JA (1966) Signal detection theory and psychophysics. New York: Wiley.

Hanes DP, Schall JD (1995) Countermanding saccades in macaque. Vis Neurosci 12:929-937.

Horwitz GD, Newsome WT (1999) Separate signals for target selection and movement specification in the superior colliculus. Science 284:1158-1161.

Johansson RS, Westling G, Backstrom A, Flanagan JR (2001) Eye-hand coordination in object manipulation. J Neurosci 21:6917-6932.

Judge SJ, Richmond BJ, Chu FC (1980) Implantation of magnetic search coils for measurement of eye position: an improved method. Vision Res 20:535-538.

Kalaska JF (1996) Parietal cortex area 5 and visuomotor behavior. Can J Physiol Pharmacol 74:483-498.

Kalaska JF, Crammond DJ (1995) Deciding not to GO: neuronal correlates of response selection in a GO/NOGO task in primate premotor and parietal cortex. Cereb Cortex 5:410-428.

Kim JN, Shadlen MN (1999) Neural correlates of a decision in the dorsolateral prefrontal cortex of the macaque. Nat Neurosci 2:176-185.

Land M, Mennie N, Rusted J (1999) The roles of vision and eye movements in the control of activities of daily living. Perception 28:1311-1328.

Logan GD, Cowan WB (1984) On the ability to inhibit thought and action: a theory of an act of control. Psychol Rev 91:295-327.

Macmillan NA, Creelman CD (1991) Detection theory: a user's guide. Cambridge, UK: Cambridge UP.

Mazzoni P, Bracewell RM, Barash S, Andersen RA (1996) Motor intention activity in the macaque's lateral intraparietal area. I. Dissociation of motor plan from sensory memory. J Neurophysiol 76:1439-1456.

Mountcastle VB, Lynch JC, Georgopoulos A, Sakata H, Acuna C (1975)
Posterior parietal association cortex of the monkey: command functions for operations within extrapersonal space. J Neurophysiol 38:871-908.

Murata A, Gallese V, Luppino G, Kaseda M, Sakata H (2000) Selectivity for the shape, size, and orientation of objects for grasping in neurons of monkey parietal area AIP. J Neurophysiol 83:2580-2601.

Musallam S, Corneil BD, Greger B, Scherberger H, Andersen RA (2004) Cognitive control signals for neural prosthetics. Science 305:258-262.

Nash J (1950) Equilibrium points in n-person games. Proc Natl Acad Sci USA 36:48-49.

Neggers SF, Bekkering H (2000) Ocular gaze is anchored to the target of an ongoing pointing movement. J Neurophysiol 83:639-651.

Pesaran B, Andersen RA (2003) Reach plan activity in macaque posterior parietal cortex during hand-eye coordination. Soc Neurosci Abstr 29:14.2.

Platt ML, Glimcher PW (1999) Neural correlates of decision variables in parietal cortex. Nature 400:233-238.

Pouget A, Snyder LH (2000) Computational approaches to sensorimotor transformations. Nat Neurosci [Suppl] 3:1192-1198.

Quian-Quiroga R, Snyder LH, Batista AP, Cui H, Andersen RA (2006) Movement intention is better predicted than attention in the posterior parietal cortex. J Neurosci 26:3615-3620.

Rushworth MF, Paus T, Sipila PK (2001) Attention systems and the organization of the human parietal cortex. J Neurosci 21:5262-5271.

Sakata H, Taira M, Murata A, Mine S (1995) Neural mechanisms of visual guidance of hand action in the parietal cortex of the monkey. Cereb Cortex 5:429-438.

Salinas E, Abbott LF (1995) Transfer of coded information from sensory to motor networks. J Neurosci 15:6461-6474.

Schall JD (2001) Neural basis of deciding, choosing and acting. Nat Rev Neurosci 2:33-42.

Scherberger H, Andersen RA (2001) Neural activity in the posterior parietal cortex during decision processes for generating visually-guided eye and arm movements in the monkey. Soc Neurosci Abstr 27:237.8.

Scherberger H, Goodale MA, Andersen RA (2003a) Target selection for reaching and saccades share a similar behavioral reference frame in the macaque. J Neurophysiol 89:1456-1466.

Scherberger H, Fineman I, Musallam S, Dubowitz DJ, Bernheim KA, Pesaran B, Corneil BD, Gillikin B, Andersen RA (2003b) Magnetic resonance image-guided implantation of chronic recording electrodes in the macaque intraparietal sulcus. J Neurosci Methods 130:1-8.

Scherberger H, Jarvis MR, Andersen RA (2005) Cortical local field potential encodes movement intentions in the posterior parietal cortex. Neuron 46:347-354.

Schultz W, Dickinson A (2000) Neuronal coding of prediction errors. Annu Rev Neurosci 23:473-500.

Shadlen MN, Newsome WT (1996) Motion perception: seeing and deciding. Proc Natl Acad Sci USA 93:628-633.

Simon O, Mangin JF, Cohen L, Le Bihan D, Dehaene S (2002) Topographical layout of hand, eye, calculation, and language-related areas in the human parietal lobe. Neuron 33:475-487.

Snyder LH, Batista AP, Andersen RA (1997) Coding of intention in the posterior parietal cortex. Nature 386:167-170.

Snyder LH, Batista AP, Andersen RA (1998) Change in motor plan, without a change in the spatial locus of attention, modulates activity in posterior parietal cortex. J Neurophysiol 79:2814-2819.

Snyder LH, Batista AP, Andersen RA (2000) Saccade-related activity in the parietal reach region. J Neurophysiol 83:1099-1102.

Sugrue LP, Corrado GS, Newsome WT (2004) Matching behavior and the representation of value in the parietal cortex. Science 304:1782-1787.

Taylor MM, Creelman CD (1967) PEST: efficient estimates on probability functions. J Acoust Soc Am 41:782-787.

Treutwein B (1995) Adaptive psychophysical procedures. Vision Res 35:2503-2522.

Wang XJ (2002) Probabilistic decision making by slow reverberation in cortical circuits. Neuron 36:955-968.

Xing J, Andersen RA (2000) Models of the posterior parietal cortex which perform multimodal integration and represent space in several coordinate frames. J Cogn Neurosci 12:601-614.

Zar JH (1999) Biostatistical analysis. Upper Saddle River, NJ: Prentice-Hall.

Zipser D, Andersen RA (1988) A back-propagation programmed network that simulates response properties of a subset of posterior parietal neurons. Nature 331:679-684. 